\title{
A Three-Part, Randomised Study to Investigate the Safety, Tolerability, Pharmacokinetics and Mode of Action of BC 007, Neutraliser of Pathogenic Autoantibodies Against G-Protein Coupled Receptors in Healthy, Young and Elderly Subjects
}

\author{
Niels-Peter Becker ${ }^{1} \cdot$ Annekathrin Haberland $^{2} \circledast$ - Katrin Wenzel ${ }^{3} \cdot$ Peter Göttel $^{4} \cdot$ Gerd Wallukat $^{3} \cdot$ Hanna Davideit $^{5,6}$. \\ Sarah Schulze-Rothe ${ }^{3}$. Anne-Sophie Hönicke ${ }^{3}$. Ingolf Schimke ${ }^{3}$. Sabine Bartel ${ }^{3}$. Matthias Grossmann ${ }^{7}$. \\ Angela Sinn ${ }^{7}$. Laura lavarone ${ }^{7}$. Jan H. Boergermann ${ }^{7} \cdot$ Kiley Prilliman $^{7,8}$. Georg Golor ${ }^{7,9}$. Johannes Müller ${ }^{10}$. \\ Susanne Becker ${ }^{11}$
}

Published online: 28 March 2020

(c) The Author(s) 2020

\begin{abstract}
Background and Objective $\mathrm{BC} 007$ is a substance with a novel and innovative mode of action for the first-time causal treatment of chronic heart failure, associated with the occurrence of autoantibodies against the $\beta 1$-adrenoceptor, and other diseases of mostly the heart and vascular system, being accompanied by the occurrence of functionally active agonistic autoantibodies against G-protein-coupled receptors ( $\left.{ }_{\mathrm{f}} \mathrm{GPCR}-\mathrm{AAb}\right)$. The proposed mechanism of action of BC 007 is the neutralisation of these pathogenic autoantibodies which stimulate the respective receptor. To evaluate the safety, tolerability, pharmacokinetics and mode of action of BC 007, single intravenous infusions of increasing concentration were given to healthy young males and healthy elderly autoantibody-negative and autoantibody-positive participants of both sexes.

Methods This study was subdivided into three parts. Part A was a single-centre, randomised, double-blind, placebo-controlled safety and tolerability study including healthy young male autoantibody-negative Whites $(N=23)$ and Asians $(N=1)$, testing doses of 15, 50 and $150 \mathrm{mg} \mathrm{BC} 007$ (Cohorts 1-3) and elderly male and female Whites $(N=8)$, testing a dose of $150 \mathrm{mg}$ BC 007 (Cohort 4), randomly assigned in a 3:1 ratio to BC 007 or placebo. Open-label Part B included fGPR-AAbpositive subjects (50 and $150 \mathrm{mg} \mathrm{BC} \mathrm{007,} \mathrm{Cohorts} 1$ and 2, respectively). Open-label Part $C$ included ${ }_{\mathrm{f}}$ GPCR-AAb-positive subjects for testing doses of 300, 450, 750,1350 mg and $1900 \mathrm{mg} \mathrm{BC} \mathrm{007.} \mathrm{Lower} \mathrm{doses} \mathrm{were} \mathrm{either} \mathrm{given} \mathrm{as} \mathrm{an} \mathrm{infusion} \mathrm{or}$ divided into a bolus plus infusion up to a dose of $300 \mathrm{mg}$ followed by a constant bolus of $150 \mathrm{mg}$ up to a dose of $750 \mathrm{mg}$, while at doses of $1350 \mathrm{mg}$ and $1900 \mathrm{mg}$ it was a slow infusion with a constant infusion rate. Infusion times increased with increasing dose from $20 \mathrm{~min}(15,50 \mathrm{or} 150 \mathrm{mg})$ to $40 \mathrm{~min}(300,450$ or $750 \mathrm{mg}), 75 \mathrm{~min}(1350 \mathrm{mg})$ and $105 \mathrm{~min}(1900 \mathrm{mg})$. Results The mean observed $\mathrm{BC} 007$ area under the concentration-time curve $\left(\mathrm{AUC}_{0-24}\right)$ increased with increasing dose in a dose proportional manner (slope estimate of 1.039). No serious adverse events were observed. Drug-related adverse events were predominantly the expected mild-to-moderate increase in bleeding time (aPTT), beginning with a dose of $50 \mathrm{mg}$, which paralleled the infusion and returned to normal shortly after infusion. ${ }_{\mathrm{f}}$ GPCR-AAb neutralisation efficiency increased with increasing dose and was achieved for all subjects in the last cohort.
\end{abstract}

Conclusion BC 007 is demonstrated to be safe and well tolerated. BC 007 neutralised ${ }_{\mathrm{f}}$ GPCR-AAb, showing a trend for a dose-response relationship in elderly healthy but ${ }_{\mathrm{f}}$ GPCR-AAb-positive subjects.

ClinicalTrials.gov Registration Number NCT02955420.

\section{Introduction}

Despite ongoing progress in pharmacological and nonpharmacological treatment of heart failure (HF) over the last three decades [1], HF is still a growing public health

Extended author information available on the last page of the article problem [2]. Up-to-date identified factors which trigger $\mathrm{HF}$ are manifold, as summarised in a comprehensive review by Hershberger et al. [3]. The impact of autoimmunity on HF pathogenesis is also subject of current discussion [4]. In particular, with the positive outcome after the removal of agonistic acting autoantibodies which stimulate the $\beta_{1}$-adrenoceptors $\left(\beta_{1}\right.$-AR), using immunoadsorption, a 


\section{Key Points}

The mean $\mathrm{BC} 007$ area under the concentration-time curves $\left(\mathrm{AUC}_{(0-\mathrm{t})}\right.$ and $\left.\mathrm{AUC}_{\text {inf }}\right)$ increased linearly with the dose. The plasma half-life time was fast and ranged from $3.0 \mathrm{~min}$ at $15 \mathrm{mg}$ in the young population up to $11 \mathrm{~min}$ at $1900 \mathrm{mg}$ BC 007 in the elderly population.

No treatment emergent adverse events (TEAEs) leading to subject discontinuation, no severe TEAEs, no serious adverse events (SAEs) and no deaths were reported throughout the entire clinical Phase I. The most common reported adverse event was a slight-to-moderate increase of the anticoagulatory effect accompanying the infusion beginning at a dose of $50 \mathrm{mg}$ which normalised quickly within minutes after infusion end.

BC 007, a new drug candidate for heart failure treatment, with innovative mode of action neutralised autoantibodies against G-protein-coupled receptors in elderly healthy G-protein-coupled receptor autoantibody-positive participants. The neutralisation lasted, in most cases, for the entire observation period of 1 month.

direct relationship between functionally active autoantibodies specific for the $\beta_{1}$-adrenoceptor $\left({ }_{f} \beta_{1}\right.$-AR-AAb) and the pathogenesis of dilated cardiomyopathy (DCM) has been seen [5]. A tremendous beneficial effect of immunoadsorption (increase in survival rate by $43.9 \%, 5$ years after treatment) was received on top of continuing conventional treatment [6, 7] and persisted over years [7]. It is very important to correctly identify the patients positive for functionally active autoantibodies, using bioassays; in patients who do not have functionally active autoantibodies, this removal therapy did not, of course, show any beneficial effect [7]. Since binding but not receptor activating $\beta_{1}$-AR-AAbs have been described [8] and also since the quality of solid phase based assays (ELISAs) in this respect are generally in question [9, 10], a correct analytic identifying the functionally active autoantibodies is a critical parameter and prerequisite for treatment success.

Independent of this described treatment success in the clinic, animal experiments have also proven the cardiotoxic effect of $\beta_{1}$-AR-AAbs when induced by immunisation with the epitope peptide of the second extracellular loop of the human $\beta_{1}$-AR, a sequence which is fully homologous to rats. Moreover, the transfer of the generated $\beta_{1}$-AR-AAb-containing serum samples to healthy control rats transferred the cardiomyopathic phenotype [11].
Immunoadsorption therapy, however, has not established itself as a routine therapy for various reasons, despite its great success.

With BC 007, a substance has now been identified capable of neutralising functionally active autoantibodies in vivo, which are directed to the G-protein coupled receptors $\left({ }_{f}\right.$ GPCR-AAbs) including the ${ }_{f} \beta_{1}$-AR-AAbs [12]. This includes ${ }_{f} \beta_{1}$-AR-AAbs which target the first and also those which target the second extracellular loop of the $\beta_{1}$-AR. In this way, all $\beta_{1}$-AR-AAb-positive HF patients are included in the possible therapy spectrum, and moreover, other cases of cardiomyopathy, such as Chagas' cardiomyopathy or peripartum cardiomyopathy, in which the $\beta_{1}$-AR-AAbs show slightly different epitopes compared to HF patients [13]. This is a tremendous advantage over a drug-development strategy which is based on the use of a specific autoantibody epitope peptide sequence only, as was done with the development of COR-1 [14], which has already failed for several reasons $[14,15]$.

BC 007 is a short single-stranded DNA sequence (15mer) which unfolds its AAB neutralising effect ex vivo and in vivo via aptamer functionality [16].

BC 007 showed no binding on a variety of tested G-protein coupled receptors itself, including the $\beta_{1}$-ARs (Eurofin Cerep Safety-screen 44 Panel). It binds the ${ }_{f}$ GPCR-AAbs. BC 007 did not show any signs of toxicity in 14-day repeat dose studies in rats (study no. SBC007S003, data not shown) and beagle dogs (study no. SBC007S004, data not shown.). In both studies, no signs of local intolerance or systemic toxicity were noted including the absence of effects on reproductive organs and signs of immune toxicology. The NoObserved-Adverse-Effect-Level (NOAEL) was concluded

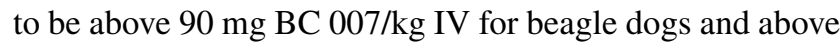

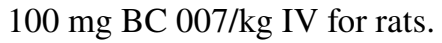

$\mathrm{BC} 007$ is, therefore, an excellent drug candidate to be tested for causal treatment of autoimmune associated chronic HF.

With the present study, the safety, tolerability, pharmacokinetics and also mode of action to neutralise ${ }_{f}$ GPCRAAbs were tested at doses between 15-1900 mg BC 007, intravenously applied over a period between 20 and $105 \mathrm{~min}$ as a bolus plus infusion or infusion only.

\section{Methods}

\subsection{Study Drug}

Clinical trial samples of BC 007 (molecular mass as sodium salt $5033.83 \mathrm{~g} / \mathrm{mol}$ ) for infusion was manufactured by BioSpring GmbH (Frankfurt am Main, Germany) and filled by LYOCONTRACT GmbH (Ilsenburg, Germany). Shortly before application the vials containing lyophilised powder 
were reconstituted using commercially available sodium chloride for injection.

\subsection{Study Population}

This study included 73 White and one Asian subjects, aged 18-75 years. Part $A$ included 32 subjects, 24 treated and eight placebos, Part $B$ included 12 subjects in two dose cohorts and Part $C$ included 30 subjects in five cohorts of six subjects each. Demographic data and an overview of baseline characteristics are shown in Table 1.

\subsection{Study Design}

The study was subdivided into three parts (Fig. 1). While Part $A$ was exclusively focused on safety and tolerability, Parts $B$ and $C$ were dedicated to additionally testing BC 007's mode of action (NCT02955420).

Part $A$ was a single-centred randomised double-blind placebo-controlled safety and tolerability test, including healthy young males, ${ }_{\mathrm{f}}$ GPCR-AAb-negative whites $(N=23)$ and Asians $(N=1)$, testing doses of 15, 50 and $150 \mathrm{mg} \mathrm{BC} 007$ intravenous with infusion (Cohorts 1-3) and elderly male and female whites $(N=8)$, testing a dose of $150 \mathrm{mg} \mathrm{BC} 007$ (Cohort 4), all randomly assigned in a 3:1 ratio to $\mathrm{BC} 007$ or placebo. Open label Part B included ${ }_{\mathrm{f}}$ GPCR-AAb-positive subjects (50 and $150 \mathrm{mg} \mathrm{BC} \mathrm{007,} \mathrm{Cohorts} 1$ and 2, respectively). Open label Part $C$ included fGPCR-AAbpositive subjects for testing doses of 300, 450, 750, 1350 and $1900 \mathrm{mg} \mathrm{BC} \mathrm{007.} \mathrm{Lower} \mathrm{doses} \mathrm{were} \mathrm{given} \mathrm{either} \mathrm{as} \mathrm{an}$ infusion (one per cohort, sentinel) or divided into a bolus plus infusion up to a dose of $300 \mathrm{mg}$ or with a constant bolus of $150 \mathrm{mg}$ up to $750 \mathrm{mg}$, three per cohort in Part $C$; while at doses of $1350 \mathrm{mg}$ and $1900 \mathrm{mg}$ it was slow infusion only. Infusion times increased with increasing dose from $20 \mathrm{~min}$ $(50$ or $150 \mathrm{mg}$ ) to $40 \mathrm{~min}(300,450$ or $750 \mathrm{mg}), 75 \mathrm{~min}$ $(1350 \mathrm{mg})$ and $105 \mathrm{~min}(1900 \mathrm{mg})$.

All three parts of this study (Parts A-C) consisted of three phases, beginning with a screening phase of up to 28 days before enrolment (day - 28 until day - 2), followed by single intravenous application assigned as described above (Day 1) and stationary follow-up for safety checks for 24 hours and outpatient follow-up safety checks at 7-10 days (Part $A$ and $B$ ) and 8-12 days (Part $C$ ) after dosing.

For Parts $B$ and $C$, these follow-up visits and an additional outpatient visit 28-32 days after dosing (Part $C$ ) were used to verify the $\mathrm{f}_{\mathrm{f}}$ GCR-AAb status.

Subject safety was carefully checked by monitoring electrocardiograms (ECG), blood pressure, injection site reactions and various laboratory safety tests checking vital signs, performing physical examinations and monitoring reports of adverse events. Blood samples were collected before the infusion began until $24 \mathrm{~h}$ thereafter for analyses of clinical chemistry, haematology, coagulation (including coagulation parameters at bedside during infusion of $1900 \mathrm{mg}$ ) and pharmacokinetics. One interim and one final follow-up visit for ${ }_{\mathrm{f}}$ GPCR-AAb status determination in subjects of Part $C$ took place approximately one week and one month, respectively, after administration of doses of $300 \mathrm{mg}$ and higher. For pharmacokinetic analysis, urine was collected.

\subsection{Pharmacokinetics, Safety and Mode of Action Evaluation}

\subsubsection{Sample Collection}

For safety laboratory analysis, blood samples for plasma concentration measurements were taken before dosing, during dosing, $4 \mathrm{~h}$ (Part A, Part B, Part C Cohorts 4-5) or $2 \mathrm{~h}$ (Part $C$ Cohorts $1-3$ ) and $24 \mathrm{~h}$ after dosing, as well as 7-10 or 8-12 days after dosing for Parts $A$ and $B$ or $C$, respectively.

For pharmacokinetic analysis, blood samples for plasma concentration measurements were taken pre-dose, at the end of the bolus or alternatively, $1 \mathrm{~min}$ after the start of the infusion for sentinel subjects (infusion only), during and immediately after the end of infusion, and also at initially shorter and later longer time intervals up to 24-h post-start bolus/ infusion in Parts $A$ and $B$.

In Part $C$, blood samples were taken pre-dose, 2 min postend of bolus or 3 min after start of infusion (when receiving infusion only). Subsequently, blood was taken at several time points during infusion followed by immediately after end of infusion and at several timepoints up to $240 \mathrm{~min}$ after start of infusion.

Urine was collected before dosing, after start of dosing every $4 \mathrm{~h}$ for $12 \mathrm{~h}$, and afterwards in one interval from 12 to $24 \mathrm{~h}$. At doses of $1350 \mathrm{mg}$ and $1900 \mathrm{mg} \mathrm{BC} \mathrm{007,} \mathrm{urine} \mathrm{was}$ collected at intervals of $0-2,2-4,4-8,8-12 \mathrm{~h}$ and $12-$ to 24-h after start infusion.

For mode of action analysis ${ }_{\mathrm{f}} \mathrm{GPCR}-\mathrm{AAb}$ neutralisation status), serum was taken before dosing, $24 \mathrm{~h}$ and about one week and one month after dosing beginning with the dose of $300 \mathrm{mg} \mathrm{BC} 007$.

\subsubsection{Pharmacokinetic Testing}

2.4.2.1 BC 007 Concentration in Plasma and Urine Hybridisation Assay for BC 007 Concentration in Plasma and Urine $\mathrm{BC} 007$ plasma and urine concentrations were estimated by Accelero ${ }^{\circledR}$ Bioanalytic $\mathrm{GmbH}$ on the basis of a validated enzyme-linked sandwich hybridisation assay using probes adapted to BC 007 within an analytical range of 5-150 ng/ $\mathrm{mL}$. 


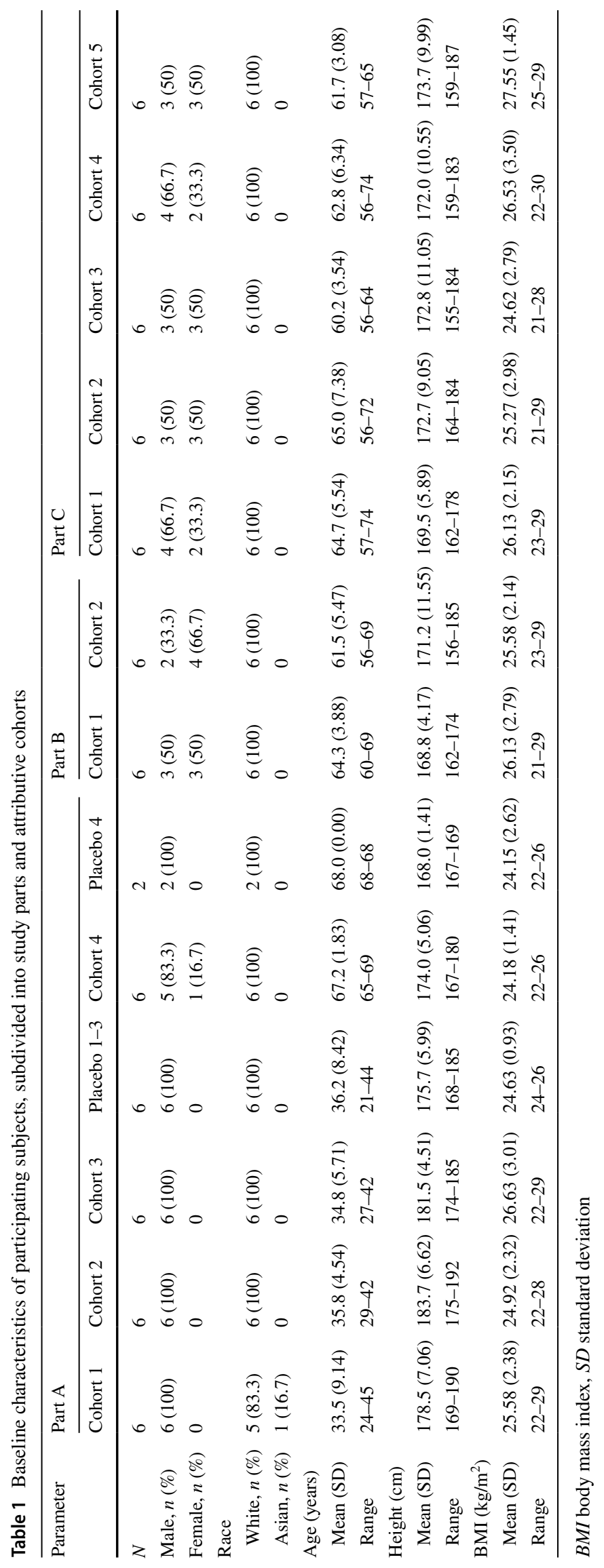


Part $\boldsymbol{A}$ [ $\boldsymbol{N}=32]$ - randomized, double-blind, placebo controlled single ascending dose study

1. $15 \mathrm{mg} \mathrm{BC} 007$

2. $50 \mathrm{mg} \mathrm{BC} 007$

3. $150 \mathrm{mg} \mathrm{BC} 007$

4. $150 \mathrm{mg} \mathrm{BC} 007$

\section{GPCR-AAb negative}

1.-3. young healthy male [18-45 y]

4. elderly male and female [55-70 y]

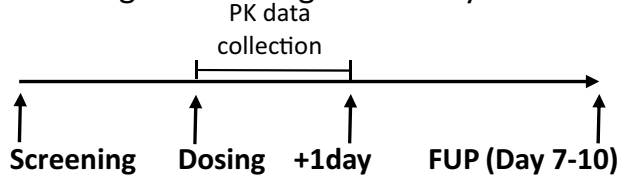

1.-4. $\mathrm{N}=2$ sentinel i.v. infusion , $\mathrm{N}=6$ i.v. bolus + infusion 20 min infusion time, 3 verum : 1 placebo

Part $B$ [ $N=12]$ - open label, sequential, single dose study

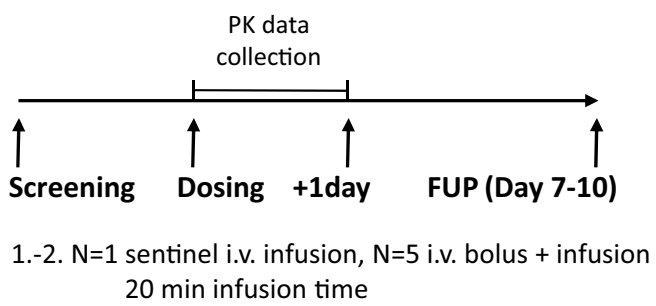

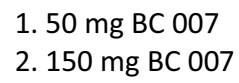

1. $50 \mathrm{mg} \mathrm{BC} 007$ 2. $150 \mathrm{mg} \mathrm{BC} 007$

\section{${ }_{f}$ GPCR-AAb positive}

1.-2. elderly male and female [55-70 y]

Part C [ $\mathbf{N = 3 0 ]}$ - open label, sequential, single dose study

1. $300 \mathrm{mg} \mathrm{BC} 007$

2. $450 \mathrm{mg} \mathrm{BC} 007$

3. $750 \mathrm{mg} \mathrm{BC} 007$

4. $1350 \mathrm{mg} \mathrm{BC} 007$

5. $1900 \mathrm{mg} \mathrm{BC} 007$

\section{f GPCR-AAb positive}

1.-5. elderly male and female [55-75 y]

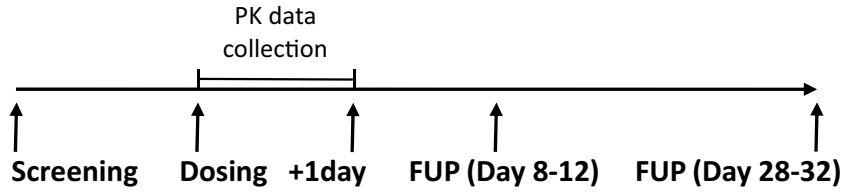

1.-3. $\mathrm{N}=3$ i.v. bolus + infusion, $\mathrm{N}=3$ i.v. infusion ( $40 \mathrm{~min}$ infusion time)

4. $\mathrm{N}=6$ i.v. infusion ( $75 \mathrm{~min}$ infusion time)

5. $\mathrm{N}=6$ i.v. infusion (105 min infusion time)

Fig. 1 Study design. FUP follow up period, i.v. intravenous, $N$ number of participants, $P K$ pharmacokinetic, $f P C R$ - $A A b$ functionally active agonistic autoantibodies against G-protein-coupled receptors

Quality control samples included three different concentrations in each sample batch. To ensure precision, the CV $\%$ had to be $\leq 20 \%$ [25\% at lower and upper limit of quantification (LLOQ/ULOQ)] for all samples. With respect to accuracy, the concentration had to be within $\pm 20 \%( \pm 25 \%$ at LLOQ/ULOQ) of the nominal level at each concentration level. At least $75 \%$ of the calibration standards and $67 \%$ of the QC samples had to meet this criterion. Furthermore, the total error of the QC sample values had to be $\leq 30 \%$ ( $\leq 40 \%$ at LLOQ/ULOQ).

Pharmacokinetic parameters maximum observed plasma concentration $\left(C_{\max }\right)$, plasma concentration at end of infusion $\left(\mathrm{C}_{\text {end_infusion }}\right)$, time corresponding to occurrence of maximum observed plasma concentration $\left(T_{\max }\right)$, area under the plasma concentration-time curve from time zero to last quantifiable concentration and from time zero to time/24-h postdose $\left(\mathrm{AUC}_{(0-\mathrm{inf})}, \mathrm{AUC}_{(0-\mathrm{t})}, \mathrm{AUC}_{(0-24)}\right)$, terminal elimination rate constant $\left(\lambda_{\mathrm{z}}\right)$, elimination half-life $\left(t_{1 / 2}\right)$, clearance $(\mathrm{CL})$ and apparent volume of distribution $\left(V_{\mathrm{z}}\right)$ were calculated on the basis of actual sampling times using WinNonlin Professional (Version 6.3). $\mathrm{AUC}_{(0-\text { inf })}$ calculation was based on a linear up/log-linear down trapezoidal method.

HPLC-Assay for the Determination of Metabolites (BC $007 n-x)$ in Plasma and Urine LGC Axiolabs GmbH was assigned for the explorative estimation of BC 007's 3 '-exonuclease cleavage products (n-1 up to n-3), developing a $\mathrm{BC}$ 007-specific anion exchange high-performance liquid chromatography (HPLC) method.

\subsubsection{Determination of the ${ }_{f}$ GPCR-AAb Status}

For ${ }_{\mathrm{f}}$ GPCR-AAb immune status assessment a qualitative cell-based assay (bioassay) was exploited.

The bioassay recorded the basal beating rate and the chronotropic response of spontaneously beating cultured neonatal cardiomyocytes to beating rate-influencing agents, such as GPCR-agonists and ${ }_{\mathrm{f}}$ GPCR-AAbs.

For this study, adapted to semiautomatic cell-beat-rate recording [17], the assay was used to identify functionally active autoantibodies against the alpha ${ }_{1}$-adrenoceptor ( $\left.\alpha_{1} \alpha_{1}-A R A A b\right)$, the beta1-adrenoceptor $\left({ }_{f} \beta_{1}-A R A A b\right)$, the beta2-adrenoceptor $\left({ }_{\mathrm{f}} \beta_{2}\right.$-AR AAb) and the endothelin 
ETA-receptor ( ${ }_{\mathrm{f}}$ ETA AAb). The first three caused a positive chronotropic cell response and the latter a negative chronotropic response. The exact assignment of the chronotropic effect to the specific autoantibodies was made through neutralising the antibody effect by administering $0.1 \mu \mathrm{mol} / \mathrm{L}$ of specific receptor blockers: prazosin, bisoprolol, ICI 118.551 and BQ 123 for ${ }_{\mathrm{f}} \alpha_{1}$-AR AAb, $\beta_{1}$-AR AAb, $\beta_{2}$-AR $A A b$ and ${ }_{f} E T A A A b$, respectively [18]. For this purpose, the blocker was added after the AAb developed its chronotropic effect on the cells. A subsequent neutralisation of the chronotropic effect by the specific blocker assigned the f GPCR-AAb to the respective receptor $[19,20]$.

\subsection{Statistics}

All statistical analyses were performed using SAS ${ }^{\circledR}$ Version 9.2 or higher (SAS Institute Inc., Cary, North Carolina, USA). All statistical tests were two-sided and performed at the $5 \%$ level of significance [95\% confidence interval (CI) was computed]. Categorical variables were described using frequencies and percentages.

\section{Results}

\subsection{Pharmacokinetics of BC 007}

The mean plasma BC 007 concentration-time profiles of all single cohorts of Parts A, B and $C$ are depicted in Figs. 2, 3, 4 in a semi-logarithmic scale.
The main information obtained from a visual inspection of the plasma concentration-time curves following administration of 15, 50 and $150 \mathrm{mg}$ infusions over $20 \mathrm{~min}$ (Part A, Fig. 2) was the rapid increase in concentrations with comparable highest concentrations for the $150 \mathrm{mg}$ dose level, whether receiving a bolus dose or not. For the $15 \mathrm{mg}$ dose level, the highest concentration was observed for the bolus group and the reverse was observed for the $50 \mathrm{mg}$ dose.

The main information from a visual inspection of the plasma concentration-time curves following administration of 50 and $150 \mathrm{mg}$ infusions over $20 \mathrm{~min}$ in elderly male and female subjects was, comparable to the Part $A$ results, an obvious rapid increase of concentrations with comparable highest concentrations, whether receiving a bolus dose or not at $50 \mathrm{mg}$ (Fig. 3a) and highest concentrations for the subjects without a bolus at $150 \mathrm{mg}$ (Fig. 3b).

Concentrations of BC 007 declined rapidly with all dose levels below the quantifiable limit at 2-h post-dose.

The main information from a visual inspection of the BC 007 plasma concentration-time curves following administration of 300,450 and $750 \mathrm{mg}$ with a bolus (150 $\mathrm{mg}$ each) and without a bolus (40 min infusion), and $1350 \mathrm{mg}$ (75 min) and $1900 \mathrm{mg}(105 \mathrm{~min})$ infusions only showed, comparable to Parts $A$ and $B$, a rapid increase in concentrations with comparable highest concentrations for the $750 \mathrm{mg}$ dose level, whether receiving a bolus dose or not (Fig. 4c). For the 300 and $450 \mathrm{mg}$ dose levels, the mean highest concentration for doses with a bolus were higher than without a bolus (Fig. 4a, b). This was all expected, given the different proportion of dose administered as a
Fig. 2 Mean plasma BC 007 concentration-time profiles of Part A, bolus with infusion (inf): solid curve; infusion only: dotted curve; subjects who received the infusion with a bolus component, $50 \%$ of the total dose was delivered as a bolus and the remainder infused over $20 \mathrm{~min}$; infusion was delivered over $20 \mathrm{~min}$. a Cohort 1 (15 mg BC 007, 6 young males ${ }_{f}$ GPCR-AAb-negative), b Cohort 2 (50 mg BC 007 , 6 young males $\mathrm{GPCR}-\mathrm{AAb}-$ negative), c Cohort 3 (150 mg BC 007, 6 young males ${ }_{f}$ GPCRAAb-negative), d Cohort 4 (150 mg BC 007, 6 elderly males and females GPCR-AAbnegative). Error bars indicate the standard deviation. $L O Q$ limit of quantification (5 ng/ $\mathrm{mL}$ ), ${ }_{f} G P C R-A A b$ functionally active agonistic autoantibodies against G-protein-coupled receptors
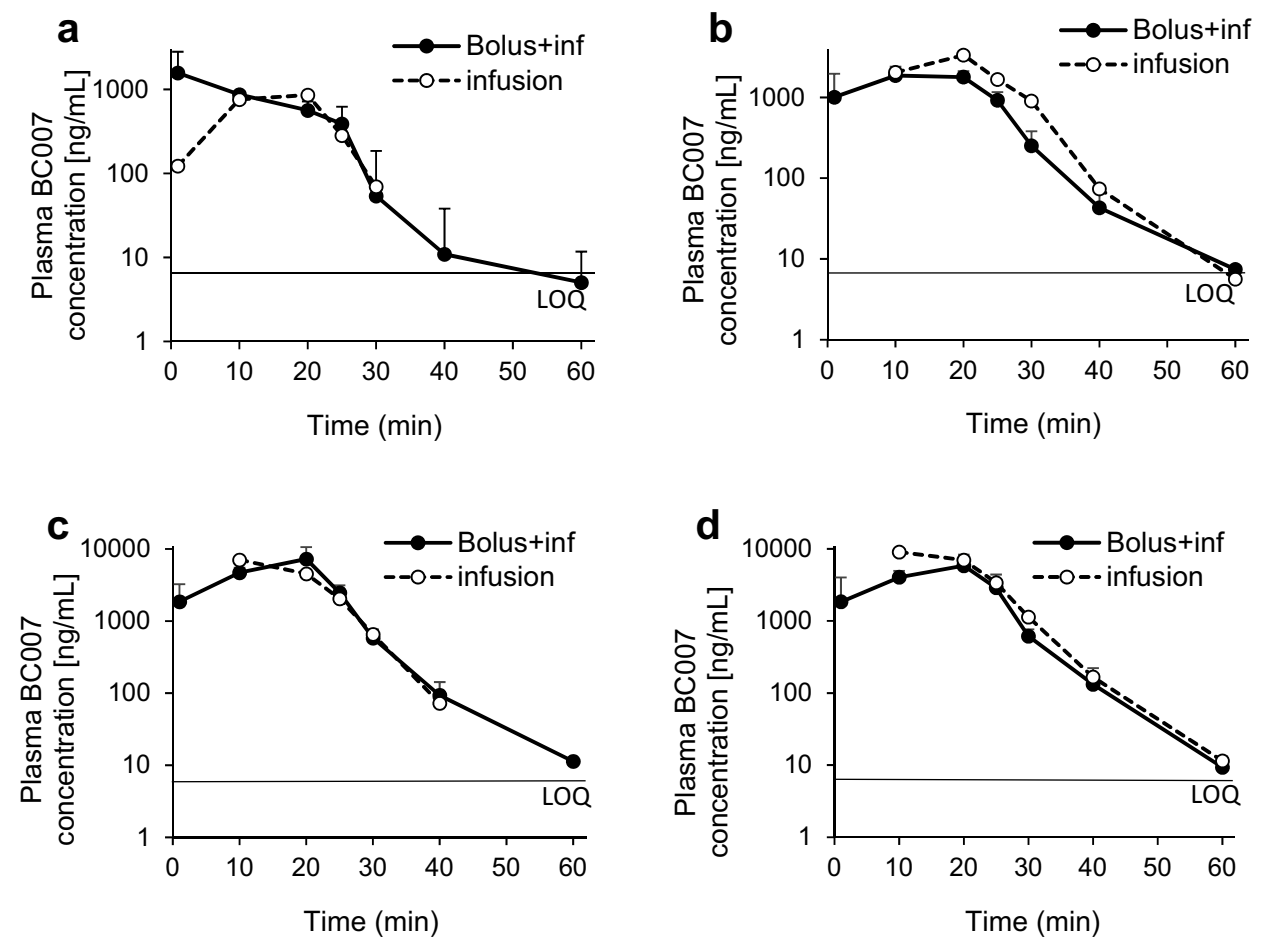


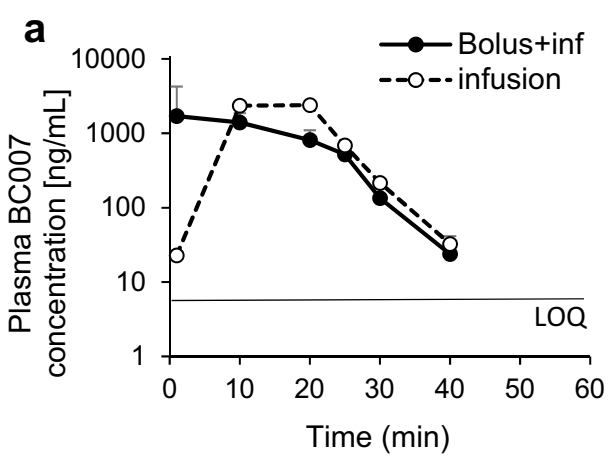

Fig. 3 Mean plasma BC 007 concentration-time profiles of Part B, bolus with infusion (inf): solid curve; infusion only: dotted curve; in subjects who received the infusion with a bolus component, 50\% of the total dose was delivered as a bolus and the remainder infused over $20 \mathrm{~min}$; infusion was delivered over $20 \mathrm{~min}$. a Cohort $1(50 \mathrm{mg}$

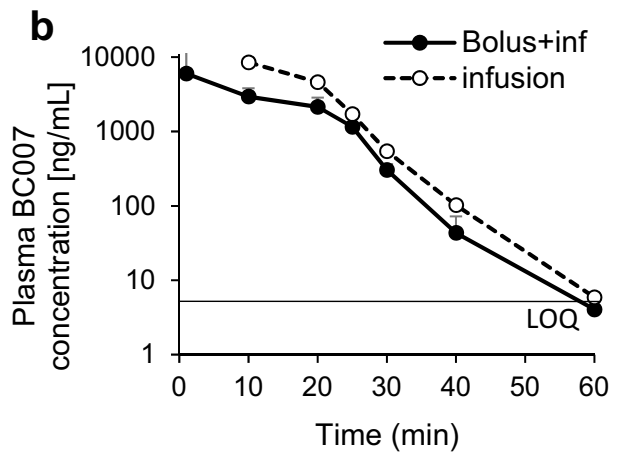

BC 007, 6 elderly males and females ${ }_{f}$ GPCR-AAb-positive), b Cohort 2 (150 mg BC 007, 6 elderly males and females ${ }_{f}$ GPCR-AAb positive). Error bars indicate the standard deviation. $L O Q$ limit of quantification $(5 \mathrm{ng} / \mathrm{mL}),{ }_{f} G P C R-A A b$ functionally active agonistic autoantibodies against G-protein-coupled receptors a

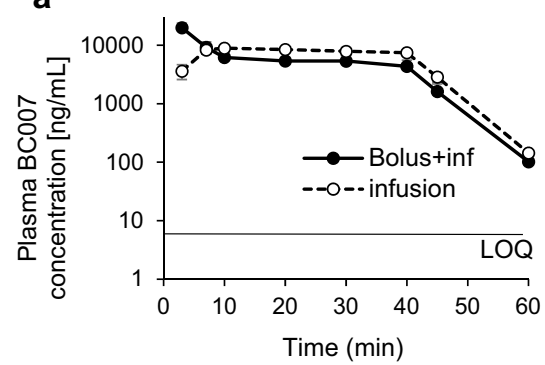

d

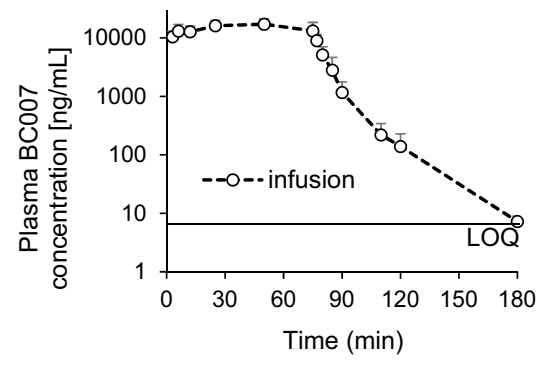

b

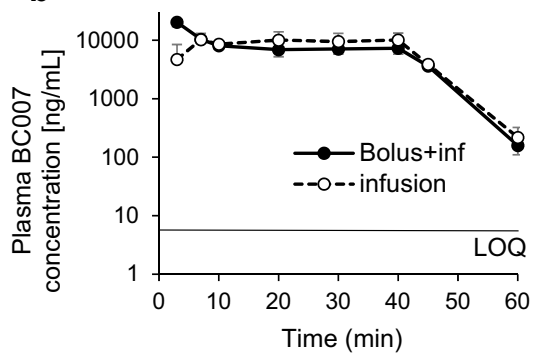

e

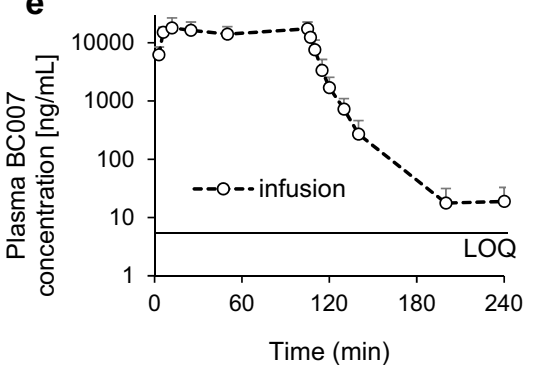

C

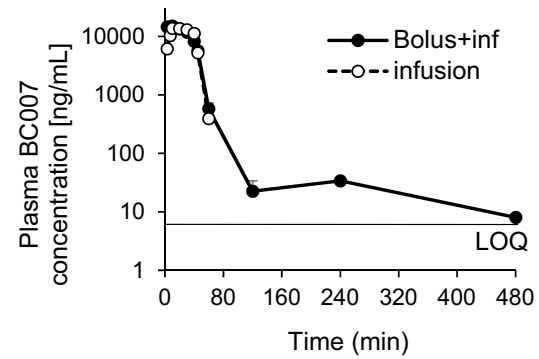

Time (min)
Fig. 4 Mean plasma BC 007 concentration-time profiles of Part $C$, bolus with infusion (inf): solid curve; infusion only: dotted curve, in subjects who received the infusion with a bolus component, $150 \mathrm{mg}$ $\mathrm{BC} 007$ was delivered as a bolus and the remainder infused over $40 \mathrm{~min}$. All cohorts comprised six elderly male and female ${ }_{\mathrm{f}} \mathrm{GPCR}-$ AAb-positive participants. a Cohort 1 (300 mg BC 007 in total, bolus $150 \mathrm{mg}$, infusion time $40 \mathrm{~min}$ ), b Cohort 2 (450 mg BC 007 in total,

bolus. At doses of $300 \mathrm{mg}$ and $450 \mathrm{mg}$ with a bolus, the plasma concentrations of BC 007 declined rapidly below the quantifiable limit at 2-h post-dose and at $450 \mathrm{mg}$ without a bolus at 4-h post-dose. For the 750 and $1350 \mathrm{mg}$ doses without a bolus, the concentrations were below the quantifiable limit by 2 -h and 4-h post-dose, respectively. Concentrations were measured for at least one subject through bolus $150 \mathrm{mg}$, infusion time $40 \mathrm{~min}$ ). c Cohort 3 (750 mg BC 007 in total, bolus $150 \mathrm{mg}$, infusion time $40 \mathrm{~min})$. d Cohort 4 (1350 mg BC 007 infusion only, infusion time $75 \mathrm{~min})$. e Cohort 5 (1900 mg BC 007 infusion only, infusion time $105 \mathrm{~min}$ ). Error bars indicate the standard deviation. $L O Q$ limit of quantification $(5 \mathrm{ng} / \mathrm{mL}),{ }_{f} G P C R$ $A A b$ functionally active agonistic autoantibodies against G-proteincoupled receptors

8-h post-dose for the $750 \mathrm{mg}$ with a bolus and through 4-h post-dose for the $1900 \mathrm{mg}$.

Plasma pharmacokinetic parameters for all study participants of Parts $A, B$ and $C$ are given in Table 2.

Across all study parts, including a steadily increasing dose (15-1900 mg) and infusion time (20-105 min) and 
also different dosing regimen (with and without bolus), $T_{\max }$ covered an expected range between 1-25 min.

The mean $C_{\max }$ values increased with the dose and ranged in Part A (15-150 mg) from 1755 to $7566 \mathrm{ng} / \mathrm{mL}$ (with bolus) and 858 to $9051 \mathrm{ng} / \mathrm{mL}$ (without bolus); in Part B (50 mg, $150 \mathrm{mg}) 2931$ and $7625 \mathrm{ng} / \mathrm{mL}$ (with bolus) and 2389 and $8495 \mathrm{ng} / \mathrm{mL}$ (without bolus); in Part C (300, 450, $750 \mathrm{mg}$ ) from 19,931 to $20,370 \mathrm{ng} / \mathrm{mL}$ (with bolus) and 9453 to $15,415 \mathrm{ng} / \mathrm{mL}$ (without bolus), and at 1350 and $1900 \mathrm{mg}$ without bolus from 18,833 to $22,207 \mathrm{ng} / \mathrm{mL}$.

The mean $\mathrm{AUC}_{(0-24)}$ values increased with the dose and ranged in Part A (15-150 mg) from 381 to $2209 \mathrm{~h} \cdot \mathrm{ng} / \mathrm{mL}$ (with bolus) and 262 to $2698 \mathrm{~h} \cdot \mathrm{ng} / \mathrm{mL}$ (without bolus); in Part B (50 mg, $150 \mathrm{mg}) 631$ and $1665 \mathrm{~h} \cdot \mathrm{ng} / \mathrm{mL}$ (with bolus) and 742 and $2105 \mathrm{~h} \cdot \mathrm{ng} / \mathrm{mL}$ (without bolus); in Part C (300, $450,750 \mathrm{mg}$ ) from 5717 to $9782 \mathrm{~h} \cdot \mathrm{ng} / \mathrm{mL}$ (with bolus) and 5709 to $8974 \mathrm{~h} \cdot \mathrm{ng} / \mathrm{mL}$ (without bolus) and at 1350 and $1900 \mathrm{mg}$ without bolus from 18,977 and 28,678 h.ng/mL.

The elimination half-life was generally short and amounted to dose-dependent increasing values between $2.9 \mathrm{~min}$ in the young population at lower doses and infusion rates and $11 \mathrm{~min}$ in the elderly population at higher doses and infusion rates, neglecting the different dosing routines. The increase in half-life with dose is likely to be dependent on the possibility of a subsequent elimination phase for a longer time at higher doses while at lower doses the halflife might be more representative of the distribution phase.

\subsection{BC 007 Dose Proportionality}

The relationship between AUC and dose was assessed using a power model to fit the natural logarithm of the parameter to the natural logarithm of the dose for the data of Parts $B$ and $C$ of the study. All data of all doses with or without bolus were included; the plot for $\mathrm{AUC}_{(0-\mathrm{t})}$ is depicted in Fig. 5.

Slope estimates revealed that the parameters $\mathrm{AUC}_{(0-\mathrm{t})}$ and $\mathrm{AUC}_{(0-\mathrm{inf})}$ (data not shown) increased in a dose-proportional manner across the dose range 50-1900 mg, showing slope estimates of 1.0390 (95\% CI 0.9578-1.1202) and 1.0388 (95\% CI 0.9563-1.1214), respectively.

With respect to $C_{0}$, this parameter was affected by the increase in concentration of bolus by parallel infusion. A proper assessment of dose proportionality of $C_{0}$ would require a bolus dose in the absence of infusion. The more than dose-proportional increase of the slope estimate of $C_{0}$ of 1.8051 across the dose range $50-750 \mathrm{mg}$ administered with a bolus, has to be, therefore, considered with caution.

Additionally, because of the change of infusion time, a power model for $C_{\max }$ has not been reported.

\subsection{BC 007 Urine Concentration}

The fraction of the dose $\left(\mathrm{f}_{\mathrm{e}}(0-24)\right.$ excreted unchanged in urine in $24 \mathrm{hrs}$ after dosing was less than $0.01 \%$ for all treatments (see Table 3 ). Renal clearance $\left(\mathrm{CL}_{\mathrm{R}}\right)$ was estimated to range from 0.0093 to $0.098 \mathrm{~mL} / \mathrm{min}$ for doses with a bolus and 0.0 to $0.2 \mathrm{~mL} / \mathrm{min}$ for subjects receiving doses without a bolus (Part A), 0.062 and $0.1 \mathrm{~mL} / \mathrm{min}$ for 50 and $150 \mathrm{mg}$ doses with a bolus and 0.025 and $0.055 \mathrm{~mL} / \mathrm{min}$ for subjects receiving the same doses without a bolus, respectively (Part $B$ ), and 0.19 to $0.82 \mathrm{~mL} / \mathrm{min}$ for doses with a bolus and 0.14 to $2.8 \mathrm{~mL} / \mathrm{min}$ for subjects receiving doses without a bolus (Part C).

\subsection{BC 007 Metabolites (n-x)}

According to Shaw et al. who investigated an ex vivo successive 3 -exonuclease degradation in monkey plasma and serum [21], the $n-x$ degradation was investigated as an exploratory parameter. In the current study, at higher doses of BC 007, a 3'-exonuclease degradation was detectable down to n-3 and amounted in total to about $7 \%$ of the plasma concentration of full-length BC 007, exemplarily shown for 1900 mg BC 007 in Fig. 6.

$\mathrm{N}-1$ was the major metabolite of the 3 '-exonulease products with an $\mathrm{AUC}_{0-\mathrm{t}}$ of 1116.3 and $1542.9 \mathrm{~h} \cdot \mathrm{ng} / \mathrm{mL}$ at a dose of 1350 and $1900 \mathrm{mg} \mathrm{BC} \mathrm{007,} \mathrm{respectively.} \mathrm{Comparable} \mathrm{to}$ the parent compound, the concentration declined quickly after stopping the infusion, showing a $t_{1 / 2}$ of about $8 \mathrm{~min}$.

\subsection{GPCR-AAb Status After Dosing (Mode of Action)}

The f GPCR-AAb neutralisation effect showed a clear tendency of a dose-effect relationship, as shown in Table 4.

At a dose of $1900 \mathrm{mg} \mathrm{BC} 007$ given as an infusion over 105 min the ${ }_{f}$ GPCR-AAbs were neutralised in all six treated subjects one month after dosing. At lower doses, the share of successfully f GPCR-AAb neutralised patients in the total number of treated patients was lower, as shown in Table 4. A more detailed breakdown according to the single ${ }_{\mathrm{f}} \mathrm{AAb}$ subtypes can be taken from Müller et al. [22].

\subsection{BC 007 Safety}

No treatment emergent adverse event (TEAE) leading to subject discontinuation, no severe TEAEs, no serious adverse events (SAEs) and no deaths were reported throughout the entire clinical Phase I.

The most common reported adverse event was a slightto-moderate anticoagulatory effect accompanying the infusion and seen via increased activated partial thromboplastin time (aPTT), increased prothrombin time (PT) and increased international normalised ratio (INR). This was due to the 


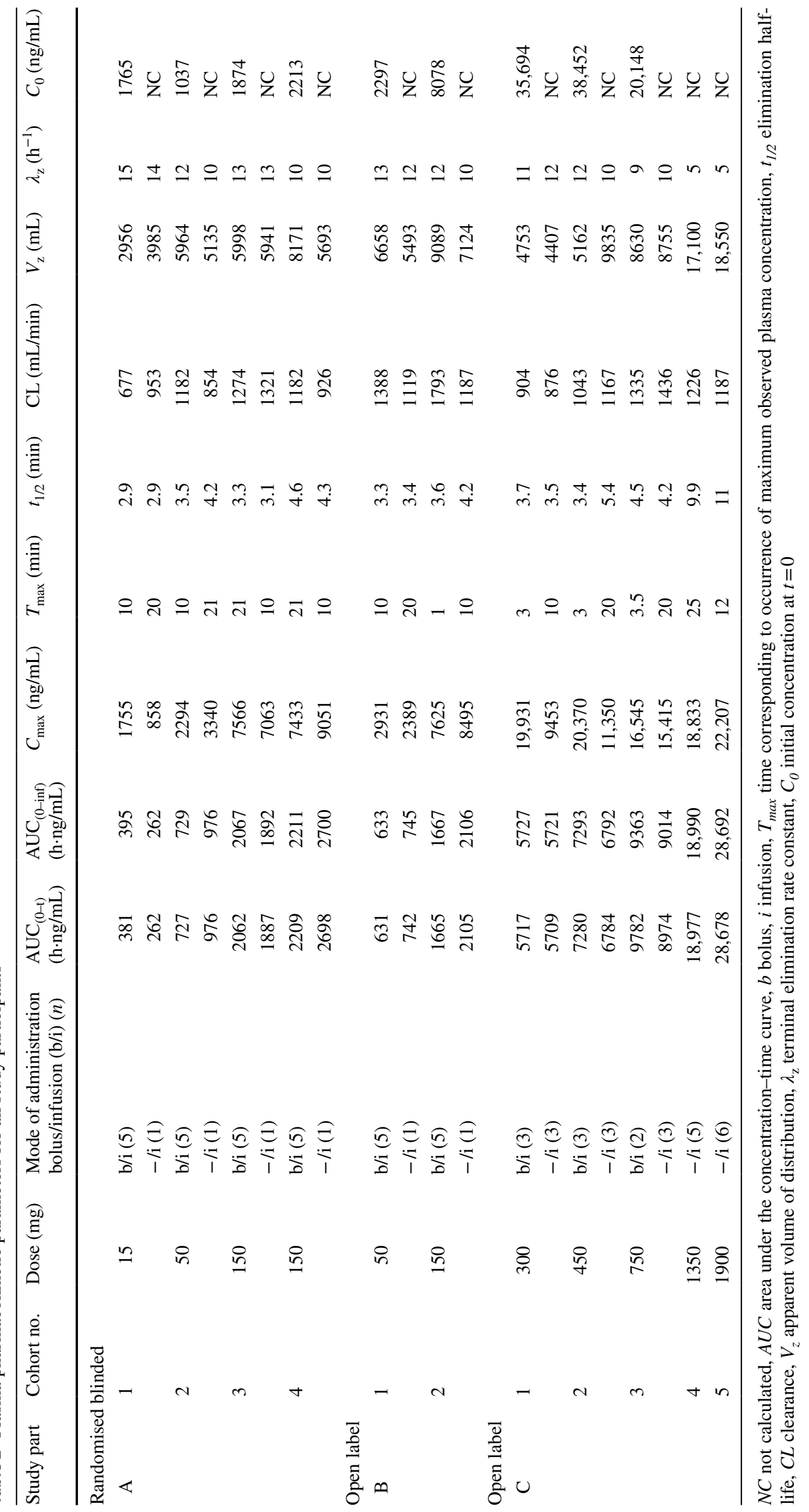


Fig. 5 Relationship between $\mathrm{BC} 007$ dose and mean area under the concentration-time curve $\left(0-24 \mathrm{~h} ; \mathrm{AUC}_{(0-24)}\right)$ following single intravenous infusions

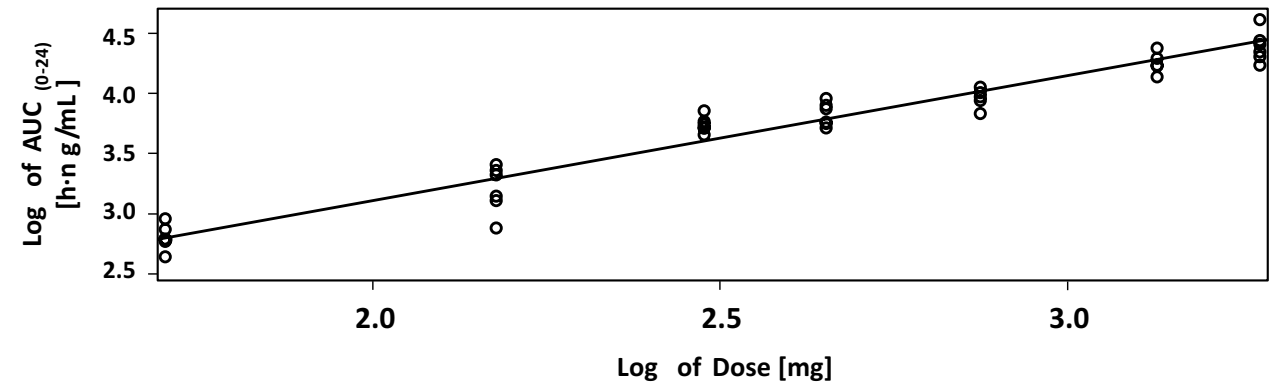

Table 3 Urine pharmacokinetic parameters for all study participants

\begin{tabular}{|c|c|c|c|c|c|c|}
\hline Study Part & Cohort no. & Dose (mg) & $\begin{array}{l}\text { Mode of administration } \\
\text { bolus/infusion } \\
(\mathrm{b} / \mathrm{i})(n)\end{array}$ & $A_{\mathrm{e}}(\mu \mathrm{g})(\mathrm{SD})$ & $f_{\mathrm{e}}(0-24)$ & $\mathrm{CL}_{\mathrm{R}}(\mathrm{mL} / \mathrm{min})$ \\
\hline \multirow[t]{8}{*}{ A } & \multirow[t]{2}{*}{1} & \multirow[t]{2}{*}{15} & $\mathrm{~b} / \mathrm{i}(5)$ & $0.00(0)$ & 0.000012 & 0.0093 \\
\hline & & & $-/ i(1)$ & $0.00(\mathrm{NC})$ & 0.0 & 0 \\
\hline & \multirow[t]{2}{*}{2} & \multirow[t]{2}{*}{50} & b/i (5) & $0.59(1.3)$ & 0.000012 & 0.017 \\
\hline & & & $-/ i(1)$ & $0.00(\mathrm{NC})$ & 0 & 0 \\
\hline & \multirow[t]{2}{*}{3} & \multirow[t]{2}{*}{150} & b/i (5) & $12.00(1.1)$ & 0.000077 & 0.098 \\
\hline & & & $-/ \mathrm{i}(1)$ & $23.00(\mathrm{NC})$ & 0.00015 & 0.2 \\
\hline & \multirow[t]{2}{*}{4} & \multirow[t]{2}{*}{150} & $\mathrm{~b} / \mathrm{i}(5)$ & $10.00(4.1)$ & 0.000067 & 0.085 \\
\hline & & & $-/ i(1)$ & $14.00(\mathrm{NC})$ & 0.000093 & 0.086 \\
\hline \multirow[t]{4}{*}{ B } & \multirow[t]{2}{*}{1} & \multirow[t]{2}{*}{50} & b/i (5) & $2.00(1.2)$ & 0.00004 & 0.062 \\
\hline & & & $-/ i(1)$ & $1.10(\mathrm{NC})$ & 0.000023 & 0.025 \\
\hline & \multirow[t]{2}{*}{2} & \multirow[t]{2}{*}{150} & b/i (5) & $8.10(1.8)$ & 0.000054 & 0.1 \\
\hline & & & $-/ i(1)$ & $7.00(\mathrm{NC})$ & 0.000046 & 0.055 \\
\hline \multirow[t]{8}{*}{$\mathrm{C}$} & \multirow[t]{2}{*}{1} & \multirow[t]{2}{*}{300} & b/i (3) & $100.0(74.0)$ & 0.00035 & 0.34 \\
\hline & & & $-/ \mathrm{i}(3)$ & $48.0(21.0)$ & 0.00016 & 0.14 \\
\hline & \multirow[t]{2}{*}{2} & \multirow[t]{2}{*}{450} & $\mathrm{~b} / \mathrm{i}(3)$ & $82.0(20.0)$ & 0.00018 & 0.19 \\
\hline & & & $-/ \mathrm{i}(3)$ & $120.0(25.0)$ & 0.00027 & 0.31 \\
\hline & \multirow[t]{2}{*}{3} & \multirow[t]{2}{*}{750} & $\mathrm{~b} / \mathrm{i}(2)$ & $540.0(\mathrm{NC})$ & 0.00064 & 0.82 \\
\hline & & & $-/ \mathrm{i}(3)$ & $560.0(97.0)$ & 0.00074 & 1.00 \\
\hline & 4 & 1350 & $-/ \mathrm{i}(5)$ & $1100.0(330)$ & 0.00081 & 0.97 \\
\hline & 5 & 1900 & $-/ i(6)$ & $4700.0(1500)$ & 0.0025 & 2.80 \\
\hline
\end{tabular}

$N C$ not calculated, $A_{e}$ cumulative amount of unchanged drug excreted into urine, $b$ bolus, $C L_{R}$ renal clearance, $f_{e}$ fraction of intravenous administered drug that is excreted unchanged in urine, $i$ infusion

fact that the sequence of $\mathrm{BC} 007$ was originally selected as a potential short-lasting thrombin inhibitor for transient anticoagulation during coronary bypass graft surgery. However, in this indication it was not successful because the lack of a persistent effect resulted in a suboptimal dosing profile; too high a dose for a therapeutic effect. This anticoagulatory effect was observed in all cohorts, beginning at a dose of $50 \mathrm{mg}$. The anticoagulatory effect normalised quickly, within minutes after the end of the infusion.

Besides this anticoagulatory effect, the following were recorded:

In Part A (24 treated subjects), no clinically significant changes in vital signs, ECG and temperature assessments were observed. Throughout all cohorts of this study part (15-150 mg BC 007), two subjects showed slightly elevated alanine aminotransferase and two subjects showed slightly elevated aspartate amino transferase. One subject reported mild palpitations and another subject a mild headache, both assessed as possibly related to investigational medical product (IMP).

In Part B (12 treated subjects, 50 and $150 \mathrm{mg}$ ), no clinically significant changes in vital signs, ECG and temperature assessments were observed. No adverse events with a possible relation to IMP were reported, except the abovementioned anticoagulatory effect. 


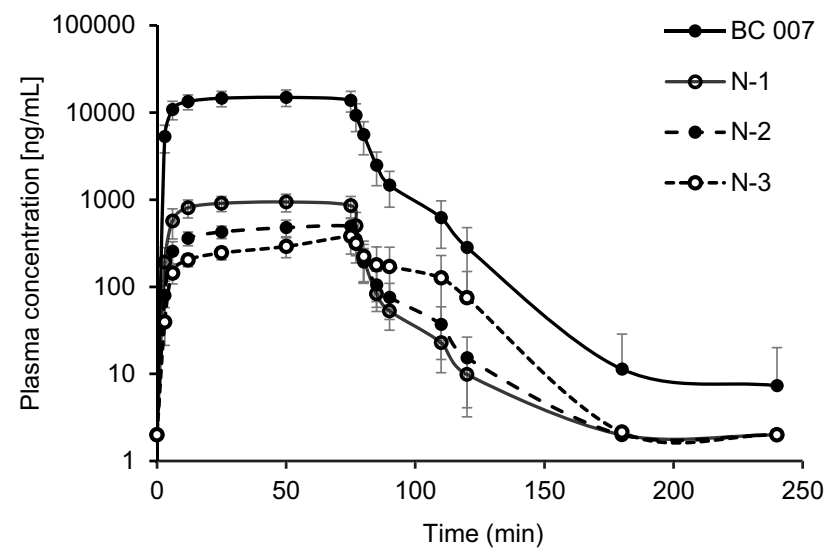

Fig. 6 Mean plasma concentration-time profiles of 3'-exonuclease degradation products of BC 007 at the applied dose of $1900 \mathrm{mg}$

In Part C (300, 450, 750, $1350 \mathrm{mg}$ and $1900 \mathrm{mg} \mathrm{BC} 007$, Cohorts $1-5$, altogether 30 treated subjects), no clinically significant changes in vital signs and temperature assessments were observed, except for one subject in Cohort 3 who showed elevated systolic and diastolic blood pressure on several measurements, which were, however, unrelated to infusion of BC 007. No clinically significant ECG changes or post-dose trends were observed in any subjects. One subject in Cohort 3 showed a QRS angle between -15 and -50 in all ECGs, unrelated to infusion of BC 007. ECGs with values between $-35^{\circ}$ and $-50^{\circ}$ were assessed as left anterior hemi block, being not clinically relevant.

Further, a first-degree atrioventricular (AV) block in one subject of Cohort 2, a first-degree AV block in another subject and prolonged QTcB/F in one subject of Cohort 4 and first degree AV block in one subject of Cohort 5, left anterior hemi block in another subject were recorded. However, all these findings were assessed as: a) not clinically relevant; and b) not related to $\mathrm{BC} 007$. One subject in Cohort
1 experienced mild dizziness with a possible relation to IMP. One had mild loose stool and a third moderate nausea after the end of the bolus injection. In Cohort $4(1350 \mathrm{mg})$, sleepiness of mild intensity in one subject was recorded. In Cohort 5 (1900 mg), four out of the six subjects experienced four AEs assessed as possibly related to IMP. However, all were the before-mentioned moderately prolonged aPTT.

In all subjects of Cohorts 4 and 5 (1350 and $1900 \mathrm{mg}$ ), an increase in uric acid was seen, beginning $50 \mathrm{~min}$ after the start of the infusion, with peak values at 120 and $110 \mathrm{~min}$ after the start of the infusion, respectively, with only slight elevation left on Day 2 and complete return to baseline on Day 8 . This increase was within the normal physiologic range [23].

Placebo data from all cohorts were pooled within each age group (young: Cohorts 1-3 or elderly: Cohort 4) for safety analyses. One subject of the younger group experienced mild headache, an unrelated TEAE.

\section{Discussion}

Neutralisation of ${ }_{\mathrm{f}}$ GPCR-AAbs, including $\beta 1-A R-A A b$, is a novel therapeutic principle, acknowledging the impact of autoantibodies on the pathogenesis of diseases of the heart and vascular system. BC 007 has shown its ${ }_{\mathrm{f}}$ GPCR-AAbneutralising effect in vitro [12], in spontaneously hypertensive rats in vivo [16] and recently with outcome benefit in ${ }_{\mathrm{f}} \beta 1$-AR-AAb positive Doberman pinschers with dilated cardiomyopathy [24]. Currently, it is under development for the causal treatment of diseases which are associated with the occurrence of ${ }_{f}$ GPCR-AAbs (for review see [25]), such as HF here the $\beta_{1}$-AR-AAb $[4,26]$.

Preclinical safety and pharmacology tests showed no signs of local intolerance or systemic toxicity in rats (study

Table 4 Dose-effect on ${ }_{\mathrm{f}}$ GPCR-AAb-neutralisation 1 day, about 1 week and 1 month after BC 007 application in healthy elderly but ${ }_{\mathrm{f}}$ GPCRAAb-positive subjects

\begin{tabular}{|c|c|c|c|c|c|c|c|}
\hline \multirow[t]{2}{*}{ Study part } & \multirow[t]{2}{*}{ Cohort no. } & \multirow[t]{2}{*}{ Dose (mg) } & \multicolumn{4}{|c|}{ fGPCR-AAb status (\# negative/\# positive) } & \multirow[t]{2}{*}{ Effect } \\
\hline & & & Before dosing & $\begin{array}{l}1 \text { day after } \\
\text { dosing }\end{array}$ & $\begin{array}{l}\text { 17-12 days after } \\
\text { dosing }\end{array}$ & $\begin{array}{l}28-32 \text { days after } \\
\text { dosing }\end{array}$ & \\
\hline \multirow[t]{2}{*}{ Part B } & 1 & 50 & $0 / 6$ & $0 / 6$ & $0 / 6$ & n.d. & \\
\hline & 2 & 150 & $0 / 6$ & $1 / 5$ & $0 / 6$ & n.d. & $(+)$ \\
\hline \multirow[t]{5}{*}{ Part C } & 1 & 300 & $0 / 6$ & $2 / 4$ & $1 / 5$ & $2 / 4$ & + \\
\hline & 2 & 450 & $0 / 6$ & $2 / 4$ & $2 / 4$ & $3 / 3$ & ++ \\
\hline & 3 & 750 & $0 / 6$ & $1 / 5$ & $2 / 4$ & $1 / 5$ & ++ \\
\hline & 4 & 1350 & $0 / 5$ & $2 / 3$ & $2 / 3$ & $4 / 1$ & ++ \\
\hline & 5 & 1900 & $0 / 6$ & $5 / 1$ & $5 / 1$ & $6 / 0$ & +++ \\
\hline
\end{tabular}

(\# negative/\# positive) number of ${ }_{\mathrm{f}} \mathrm{GPCR}-\mathrm{AAb}$-negative/number of ${ }_{\mathrm{f}} \mathrm{GPCR}-\mathrm{AAb}$-positive, $m g$ milligram, n.d. not determined, no. number,,++++ , $+++{ }_{\mathrm{f}}$ GPCR-AAb-neutralization effect, $f$ GPCR-AAb functionally active agonistic autoantibodies against G-protein-coupled receptors 
no. SBC007S003, data not shown) and dogs (study no. SBC007S004, data not shown).

This clinical study Phase I was designed to test the safety and tolerability of BC 007 in humans as well as the mode of action when intravenously applied. It was, therefore, also designed to find an appropriate dosing regimen for ${ }_{f}$ GPCRAAb-positive patients. With the latter, the dose was the primary focus of interest; second, was the application mode, which means infusion time and combination with or without a bolus.

Overall, the AUC increased in a dose-proportional manner across the dose range 50-1900 mg, including all data.

The plasma clearance showed values in the range 0.68-1.79 L/min, obviously not depending on the dose.

Elimination was rapid and increased with increasing dose from $2.9 \mathrm{~min}$ at $15 \mathrm{mg} \mathrm{BC} 007$ in the young population up to $11 \mathrm{~min}$ at $1900 \mathrm{mg}$ in the elderly. The increase in halflife with dose is likely to be dependent on the possibility of a subsequent elimination phase for a longer time at higher doses, while at lower doses the half-life might be more representative of the distribution phase.

The apparent volume of distribution is small but increased from about $3 \mathrm{~L}$ at a dose of $15 \mathrm{mg}$ in the young population up to $18.5 \mathrm{~L}$ at $1900 \mathrm{mg}$ BC 007 in the elderly, as it was derived from half-life, increasing with dose. A generally small apparent volume of distribution is typical for intravascularly confined highly water-soluble compounds when plasma-protein binding is low.

Comparing the mean values of the essential pharmacokinetic parameters between infusion with and without bolus especially in Part C (300, 450 and $750 \mathrm{mg} \mathrm{BC} \mathrm{007;} \mathrm{in} \mathrm{this}$ study part a constant bolus of $150 \mathrm{mg}$ and subgroup sizes comparable), no trend for one or the other group (with or without bolus) with respect to AUC, CL and apparent distribution volume became visible, except for $T_{\max }$, of course, which was reached immediately after bolus application compared to infusion where $T_{\max }$ was 10 and 20 min conforming to expectations, since $T_{\max }$ is expected to be reached within the end of the infusion when a steady state is achieved based on 3-5 half-lives. The $\mathrm{AUC}_{(0-24)}$ values were identical to the $\mathrm{AUC}_{(0-\text { inf })}$ for all treatments, as expected, given the short half-life of the compound.

$C_{\max }$ was lower with the infusion only at the 300 and $450 \mathrm{mg}$ group, (with bolus vs without bolus: 19,931 vs $9453 \mathrm{ng} / \mathrm{mL}$ and 20,370 vs $11,359 \mathrm{ng} / \mathrm{mL}$, respectively), an effect which disappeared at $750 \mathrm{mg} \mathrm{BC} 007$ (16,545 vs $15,415 \mathrm{ng} / \mathrm{mL})$. Since the bolus was kept constant at $150 \mathrm{mg}$ and infusion time increased, its influence diminished with the increasing total dose. In general, at the higher dose of $750 \mathrm{mg}$ the differences disappeared. Restrictions with respect to the increase of the bolus were partially made as a precaution on the basis of observations by Gilbert et al. [27] who reported a: 'hypersensitivity reaction that occurred in 1 subject at a dose...given by a rapid intravenous push'. Thereafter, the drug was diluted and 'the rate of administration was reduced...it was given as a slow intravenous bolus...', avoiding such incidents.

It was also decided to continue the dose escalation with infusion without bolus (1350 $\mathrm{mg}$ and $1900 \mathrm{mg}$ ) from the pharmacokinetic perspective. Doing this, the infusion time was prolonged from $40 \mathrm{~min}$ at $750 \mathrm{mg} \mathrm{BC} 007$ to $75 \mathrm{~min}$ at $1350 \mathrm{mg}$ and $105 \mathrm{~min}$ at $1900 \mathrm{mg}$, this way keeping the infusion rate constant at about $18 \mathrm{mg} / \mathrm{min}$. In this way, safety and pharmacodynamic aspects were considered at the same time. From the pharmacokinetic perspective, the increased duration of BC 007 steady state was more likely to neutralise f GPCR-AAbs bound to the GPCR-receptor.

With respect to metabolism, the proportion of $7 \%$ of 3 '-exonuclease cleaved compound is low, especially since Shaw et al. published an effective 3 '-exonuclease decay in monkey plasma and serum in 1995 [21]. It was, therefore, also already looked for further down breakdown products, identifying the increase of nucleobase decay products immediately after the start of the infusion, which was described in detail by Davideit et al. [23]. This fast and full degradation down to nucleic base degradation products in humans was an astonishing fact and one of the first reports about the fate of DNA-drugs in humans.

Looking at the influence of age on pharmacokinetic parameters, the $150 \mathrm{mg}$ groups of $\mathrm{fPCR}-\mathrm{AAb}$-negative subjects of Part A can be compared. Following the $150 \mathrm{mg}$ dose with a bolus ( 5 participants each), the arithmetic mean results for $C_{\max }$ were slightly higher in healthy males aged 18-45 years (Cohort 3 ) compared to healthy males $(N=3)$ and females $(N=1)$ aged 55-70 years (Cohort 4$)$ and the AUC parameters were slightly lower for Cohort 3. The elderly subject $(N=1)$ receiving $150 \mathrm{mg}$ without a bolus had approximately $43 \%$ higher AUC values and a $28 \%$ higher $C_{\max }$ than the young subject $(N=1)$ receiving $150 \mathrm{mg}$ without a bolus. As expected, the clearance was approximately $43 \%$ higher for the young subject receiving $150 \mathrm{mg}$ without a bolus compared to the elderly subject receiving the same treatment. However, given the limited sample size $(N=1)$, this difference cannot be considered statistically significant, even though lower clearance is expected in an elderly population.

The higher dose, especially of $1900 \mathrm{mg}$, showed a satisfying $\mathrm{GPCR}-\mathrm{AAb}$-neutralising effect. In general, a trend for a dose-effect relationship became clearly visible. The ${ }_{f}$ GPCRAAb-positive participants were, however, healthy people. It is very likely that the occurrence of autoantibodies is a result of a very early autoimmune response. As previously mentioned [22], it can be speculated that, since during an early immune response, normally a multiplicity of low-avidity immunoglobulin ( $\mathrm{IgG}$ ) antibodies target a multitude of separate epitopes of a target molecule, only the subsequent clonal 
selection (beginning pathogenesis) increases the avidity of the antibodies and limits the number of epitopes [28]. This might determine a dosing regimen and has to be investigated in future effectivity tests when testing different indications.

Nevertheless, these existing mode of action data combined with the excellent safety profile support the application of $1350 \mathrm{mg} \mathrm{BC} 007$ for the neutralisation of ${ }_{\mathrm{f}} \beta 1$-ARAAbs in autoantibody positive HF patients (Phase IIa, in progress, NCT04192214), compromising and combining the neutralisation of $80 \%$ of all ${ }_{\mathrm{f}}$ GPCR-AAbs (4 out of 5) one month after application and the complete neutralisation of ${ }_{f} \beta 1$-AR-AAbs at each tested dose beginning with $450 \mathrm{mg}$ [22].

The observed good safety profile up to the highest tested amount of $1900 \mathrm{mg}$ at an infusion rate of $18 \mathrm{mg} / \mathrm{mL}$ permitted the use of $1350 \mathrm{mg} \mathrm{BC} 007(18 \mathrm{mg} / \mathrm{mL})$ for testing the persistence of the ${ }_{\mathrm{f}} \beta 1-\mathrm{AR}-\mathrm{AAb}$ neutralisation in HF patients.

BC 007 proved to be safe and well tolerated. No SAEs were observed. The main drug-related adverse event was an infusion accompanying a slight-to-moderate anticoagulatory effect which normalised shortly after the end of the infusion.

\section{Conclusion}

BC 007 is a substance with a novel mode of action for the causal treatment of diseases associated with the occurrence of pathogenic functionally acting autoantibodies against G-protein coupled receptors, which mostly affect the heart and vascular system (e.g. heart failure and pulmonary hypertension). BC 007 is applied as infusion. In this Phase 1 study, BC 007 proved to be safe, well tolerated and demonstrated its ability to neutralise the autoantibodies. BC 007's half-life time was short and was between 3 and $11 \mathrm{~min}$ in all conditions tested. The area under the concentration-time curves (AUC) increased linearly with the dose. Based on this Phase I study results, a currently ongoing Phase IIa study has been established, testing its effect on ${ }_{\mathrm{f}} \beta_{1}$-AR-AAb-associated heart failure patients.

Acknowledgements This manuscript was proofread by Proof-ReadingService, PRS.

\section{Compliance with Ethical Standards}

Funding This study and the Open Access fee were funded by the Berlin Cures Holding AG. The authors have no other relevant affiliations or financial involvement with any organisation or entity with a financial interest in or financial conflict with the subject or materials discussed in the manuscript apart from those which are disclosed.

Conflict of interest Niels-Peter Becker, Annekathrin Haberland, Katrin Wenzel, Peter Göttel, Gerd Wallukat, Hanna Davideit, Sarah Schulze-Rothe, Anne-Sophie Hönicke, Ingolf Schimke, Sabine Bar- tel, Johannes Müller, Susanne Becker are employed at Berlin Cures GmbH. Annekathrin Haberland, Peter Göttel, Gerd Wallukat, Ingolf Schimke, Johannes Müller are shareholders of Berlin Cures Holding AG, the parent company of the Berliner branch Berlin Cures GmbH. All other authors have nothing to declare.

Ethical standards The study was conducted in accordance with the principles set forth in the Declaration of Helsinki as amended in 1996, the Guidelines of the International Council for Harmonisation (ICH) on Good Clinical Practice (GCP) (CPMP/ICH/135/95), as well as the requirements of the European Union Data Protection Directive 95/46/ EC and other applicable regulatory requirements. The study was approved by the Berlin ethics commision "Landesamt für Gesundheit und Soziales Berlin, Ethikkommission des Landes Berlin".

Informed consent Before each subject was enrolled in this clinical study, written informed consent was obtained according to the regulatory and legal requirements of the country which hosted the study.

Open Access This article is licensed under a Creative Commons Attribution-NonCommercial 4.0 International License, which permits any non-commercial use, sharing, adaptation, distribution and reproduction in any medium or format, as long as you give appropriate credit to the original author(s) and the source, provide a link to the Creative Commons licence, and indicate if changes were made. The images or other third party material in this article are included in the article's Creative Commons licence, unless indicated otherwise in a credit line to the material. If material is not included in the article's Creative Commons licence and your intended use is not permitted by statutory regulation or exceeds the permitted use, you will need to obtain permission directly from the copyright holder.To view a copy of this licence, visit http://creativecommons.org/licenses/by-nc/4.0/.

\section{References}

1. McMurray JJV, Adamopoulos S, Anker SD, Auricchio A, Böhm M, Dickstein K, et al. ESC guidelines for the diagnosis and treatment of acute and chronic heart failure 2012: the Task Force for the Diagnosis and Treatment of Acute and Chronic Heart Failure 2012 of the European Society of Cardiology. Developed in collaboration with the Heart Failure Association (HFA) of the ESC. Eur J Heart Fail. 2012;14:803-69.

2. Hunt SA, Abraham WT, Chin MH, Feldman AM, Francis GS, Ganiats TG, et al. 2009 focused update incorporated into the ACC/AHA 2005 Guidelines for the Diagnosis and Management of Heart Failure in Adults: a Report of the American College of Cardiology Foundation/American Heart Association Task Force on practice guidelines developed in collaboration with the International Society for Heart And Lung Transplantation. J Am Coll Cardiol. 2009;53:e1-90.

3. Hershberger RE, Hedges DJ, Morales A. Dilated cardiomyopathy: the complexity of a diverse genetic architecture. Nat Rev Cardiol. 2013;10:531-47.

4. Alvarez P, Briasoulis A. Immune modulation in heart failure: the promise of novel biologics. Curr Treat Options Cardiovasc Med. 2018;20:26.

5. Wallukat G, Müller J, Hetzer R. Specific removal of beta1adrenergic autoantibodies from patients with idiopathic dilated cardiomyopathy. N Engl J Med. 2002;347:1806.

6. Müller J, Wallukat G, Dandel M, Bieda H, Brandes K, Spiegelsberger $\mathrm{S}$, et al. Immunoglobulin adsorption in patients with idiopathic dilated cardiomyopathy. Circulation. 2000;101:385-91. 
7. Dandel M, Wallukat G, Englert A, Lehmkuhl HB, Knosalla C, Hetzer R. Long-term benefits of immunoadsorption in $\beta(1)$ adrenoceptor autoantibody-positive transplant candidates with dilated cardiomyopathy. Eur J Heart Fail. 2012;14:1374-88.

8. Bornholz B, Roggenbuck D, Jahns R, Boege F. Diagnostic and therapeutic aspects of $\beta 1$-adrenergic receptor autoantibodies in human heart disease. Autoimmun Rev. 2014;13:954-62.

9. Haberland A, Muller J, Wallukat G, Wenzel K. Antigen-free control wells in an ELISA set-up for the determination of autoantibodies against $\mathrm{G}$ protein-coupled receptors-a requisite for correct data evaluation. Anal Bioanal Chem. 2018;410:5101-5.

10. Oaks M, Michel K, Downey FX, Thohan V. Xenoreactive antibodies and latent fibrin formation in VAD and cardiac transplant recipients can confound the detection and measurement of antiAT1R antibodies. Am J Transplant. 2018;18:2763-71.

11. Jahns R, Boivin V, Hein L, Triebel S, Angermann CE, Ertl G, et al. Direct evidence for a beta 1-adrenergic receptor-directed autoimmune attack as a cause of idiopathic dilated cardiomyopathy. J Clin Invest. 2004;113:1419-29.

12. Haberland A, Holtzhauer M, Schlichtiger A, Bartel S, Schimke I, Muller J, et al. Aptamer BC 007-a broad spectrum neutralizer of pathogenic autoantibodies against G-protein-coupled receptors. Eur J Pharmacol. 2016;789:37-45.

13. Haberland A, Wallukat G, Schimke I. The patent situation concerning the treatment of diseases associated with autoantibodies directed against G-protein-coupled receptors. Pharm Pat Anal. 2013;2:231-48.

14. Nnane IP, Plotnikov AH, Peters G, Johnson M, Kojak C, Vutikullird A, et al. Pharmacokinetics and safety of single intravenous doses of JNJ-54452840, an Anti- $\beta 1$-adrenergic receptor antibody cyclopeptide, in healthy male Japanese and Caucasian participants. Clin Pharmacokinet. 2016;55:225-36.

15. Stork S, Plotnikov AN, Peters G, Davies BE, Nnane I, Rivas D, et al. Efects of JNJ-54452840, an anti- $\beta 1$ receptor antibody cyclopeptide in heart failure patients: a randomized, double-blind, parallel-group, phase-2 pilot study. Cardiovasc Pharmacol Open Access. 2016;5:4. https://doi.org/10.4172/2329-6607.1000190.

16. Wallukat G, Müller J, Haberland A, Berg S, Schulz A, Freyse E-J, et al. Aptamer BC007 for neutralization of pathogenic autoantibodies directed against G-protein coupled receptors: a vision of future treatment of patients with cardiomyopathies and positivity for those autoantibodies. Atherosclerosis. 2016;244:44-7.
17. Davideit H, Haberland A, Bartel S, Schulze-Rothe S, Müller J, Wenzel K. Determination of agonistically acting autoantibodies to the adrenergic beta-1 receptor by cellular bioassay. Methods Mol Biol. 2019;1901:95-102.

18. Wallukat G, Prüss H, Müller J, Schimke I. Functional autoantibodies in patients with different forms of dementia. PLoS One. 2018;13:e0192778.

19. Wenzel K, Schulze-Rothe S, Haberland A, Müller J, Wallukat G, Davideit H. Performance and in-house validation of a bioassay for the determination of beta1-autoantibodies found in patients with cardiomyopathy. Heliyon. 2017;3:e00362.

20. Wallukat G, Wenzel K, Schimke I. Analytics of functional autoantibodies in patients with chagas disease. Methods Mol Biol. 2019;1955:247-61.

21. Shaw JP, Fishback JA, Cundy KC, Lee WA. A novel oligodeoxynucleotide inhibitor of thrombin. I. In vitro metabolic stability in plasma and serum. Pharm Res. 1995;12:1937-42.

22. Muller J, Haberland A, Becker N-P, et al. The DNA-based therapeutic agent $\mathrm{BC} 007$ completely neutralizes agonistic autoantibodies directed against $\beta 1$-adrenoceptors: results of a phase 1 trial. J Am Coll Cardiol. 2018;71(11 Supplement):A645.

23. Davideit H, Becker S, Muller J, Becker N-P, Gottel P, Abay A, et al. In-vivo degradation of DNA-based therapeutic BC 007 in humans. Eur J Drug Metab Pharmacokinet. 2019;44:567-78.

24. Werner S, Wallukat G, Becker N-P, et al. The aptamer BC 007 for treatment of dilated cardiomyopathy: evaluation in Doberman Pinschers of efficacy and outcomes. ESC Heart Fail. 2020. https ://doi.org/10.1002/ehf2.12628.

25. Wallukat G, Schimke I. Agonistic autoantibodies directed against G-protein-coupled receptors and their relationship to cardiovascular diseases. Semin Immunopathol. 2014;36:351-63.

26. Luft FC. Activating autoantibodies and cardiovascular disease. Physiology (Bethesda). 2013;28:254-61.

27. Gilbert JC, DeFeo-Fraulini T, Hutabarat RM, Horvath CJ, Merlino PG, Marsh HN, et al. First-in-human evaluation of anti von Willebrand factor therapeutic aptamer ARC1779 in healthy volunteers. Circulation. 2007;116:2678-86.

28. DeFranco AL. The germinal center antibody response in health and disease. F1000Res. 2016. https://doi.org/10.12688/f1000resea rch.7717.1. 


\section{Affiliations}

Niels-Peter Becker ${ }^{1} \cdot$ Annekathrin Haberland $^{2}$ (1) $\cdot$ Katrin Wenzel $^{3} \cdot$ Peter Göttel $^{4}$. Gerd Wallukat ${ }^{3} \cdot$ Hanna Davideit $^{5,6}$. Sarah Schulze-Rothe ${ }^{3}$. Anne-Sophie Hönicke ${ }^{3}$. Ingolf Schimke ${ }^{3}$. Sabine Bartel ${ }^{3}$. Matthias Grossmann ${ }^{7}$. Angela Sinn ${ }^{7}$. Laura lavarone ${ }^{7}$. Jan H. Boergermann ${ }^{7} \cdot$ Kiley Prilliman $^{7,8} \cdot$ Georg Golor $^{7,9}$. Johannes Müller ${ }^{10}$. Susanne Becker ${ }^{11}$

$\triangle$ Annekathrin Haberland haberland@berlincures.de

1 Berlin Cures GmbH, Dept. Regulatory Affairs, Knesebeck Str. 59-61, 10719 Berlin, Germany

2 Berlin Cures GmbH, Dept. Regulatory Affairs, Robert-Rössle-Str. 10, 13125 Berlin, Germany

3 Berlin Cures GmbH, Laboratory, Robert-Rössle-Str. 10, 13125 Berlin, Germany

4 Berlin Cures GmbH, COO, Knesebeck Str. 59-61, 10719 Berlin, Germany

5 Berlin Cures GmbH, Dept. Quality Management, Robert-Rössle-Str. 10, 13125 Berlin, Germany
6 Present Address: Life Molecular Imaging GmbH, Berlin, Germany

7 Parexel International GmbH, Berlin, Germany

8 Present Address: Veristat, Southborough, MA, United States

9 Present Address: Biokinetica GmbH, Berlin, Germany

10 Berlin Cures GmbH, CEO, Knesebeck Str. 59-61, 10719 Berlin, Germany

11 Berlin Cures GmbH, Clinical Operations, Knesebeck Str. 59-61, 10719 Berlin, Germany 